\title{
Gurung music in terms of gender
}

This article demonstrates various aspects of how gender relates to music-making - to the conceptualization of music, musical esthetics, musical behavior and social norms involved in it - and to cultural changes reflected in music; the gender order crucial to a society is present in the musical behavior of its people. Gender is a cultural factor which greatly influences music-making and vice versa, music acts as an indicator of gender roles as well as an allowed area of their transformation. ${ }^{1}$

This study will assess the role of gender in Gurung ${ }^{2}$ musical behavior. The development of gender roles and their reflections in music-making are examined from Gurung childhood to adulthood.

\section{Gurung gender roles}

The conceptualising of the rhythmic patterns played as the accompaniment to the Serko dances in the rites after death nicely replicates the division of gender concepts in Gurung usage. The rhythmic patterns with "simple" beat are conceptualised as male patterns and those with "double" beat as female ones. The presence of both kinds of patterns makes the performance "complete". This reflects the general attitude towards the sexes in the Gurung community; each gender has its own functions and place in the social system and interaction and both are required for completeness.

One of the narrations belonging to the reportoire of Gurung poju shamans, the thà wàwa ("casting out the evil") states the traditional order of Gurung gender relations:

Womb preceding wood is proper

Wood preceding womb is improper,

1) For more about the interrelatedness of gender structure and music, see Koskoff 1987, and Herndon and Ziegler 1990.

2) For more about the Gurung music culture, music and musical change, see Moisala 1991. The Gurungs are one of the ethnic groups of Nepal. Most of the total Gurung population of 170000 lives in the mountain area of mid-Nepal. 


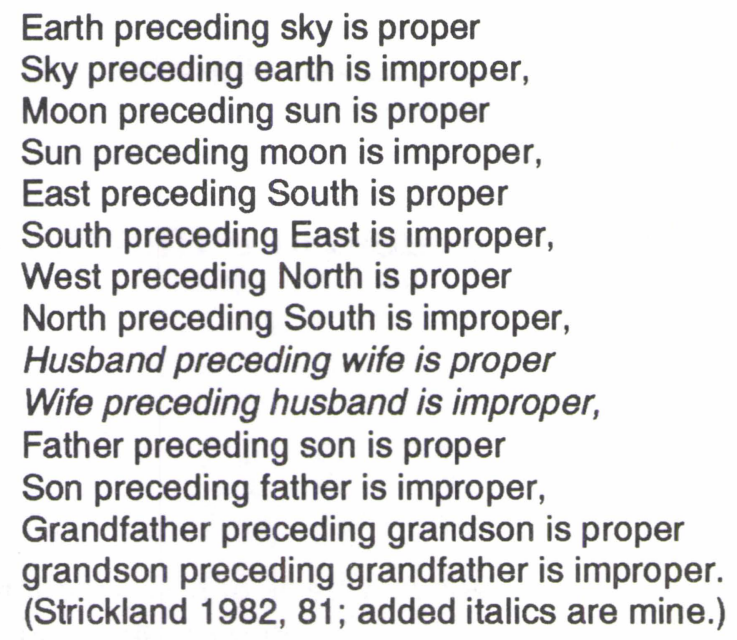

Ellen Andors notes that many Gurung men and women state that males and females are equal $(1976,193)$. According to my experience, many were also aware of the imbalance between the sexes. The men especially were aware of the privileges they have. For instance, in the course of my first field trip in 1975, when my husband came with me to wash the clothes at the public well, some men came to him in secret and asked him not to do it anymore, because their wives "had asked them to do the same".

The gender roles of the Gurung culture also influenced the way I was percieved by the villagers and, in turn, my work in the field. In 1975-76, the villagers obviously had great difficulties in categorizing me according to gender. Because of my research work, I could not perform the role and activities of a Gurung female. My hairstyle, dress and personal ornaments were also different. Also because of my childlessness I could not be percieved as an adult woman. Presumably all these factors led to me being treated, to a great extent, as a young male; I was allowed to attend all-male events, such as the meal in the bride's home, but was not considered as an equal of men in conversational situations. The females of the village, for their part, acted shyly towards me and did not easily open up for discussions.

Conversely, in 1985, when I visited the village with my eight-year-old son and a female friend, I lost some of the male contacts I had had. However, I had great success among the females. Every evening women came to see us. All of them remembered my first visit and now wanted to make contact. Very openly they told their life stories and described their attitudes and emotional experiences. They were also curious about my life and fully enjoyed the fact that I had a son.

\section{Musical life path of the different genders}

Gurung children are brought up with emphasis on different aspects according to gender. From early childhood, small group solidarity, household activities and 
"background" support are emphasized in the upbringing of a female child. The early life of a Gurung female establishes activities and attitudes that are directed toward her envisioned future as a wife and mother. The girls are not encouraged to study at school; ${ }^{3}$ on the contrary, if the girl shows an interest in studying, this is discouraged by referring to her future marriage.

Girls are expected to carry out many lighter household tasks. They look after younger children, carry water and help their mothers in other household activities. From the age of eight or nine, they gather with their friends at so-called Rodi ${ }^{4}$ houses in the evenings, often also staying there overnight.

A Rodi is a socially arranged institution for the evening gatherings of the Gurung youth. ${ }^{5}$ Rodîs develop out of a loose network of girl friends, who find a suitable house for their evening gatherings. The elders of the house, who are called a Rodī mother and a Rodī father (in Gurung, rotsyo-am and rotsyo-ab, and in Nepalese rodi-ama and rodī-aba, respectively), are expected to keep an eye on the behavior of the group. Often, the Rodi mother sleeps in the same room in which the youth socialize. When a Rodi group is established, boys begin to visit it. Girls expect and hope for them to come. Together they sing, play, discuss and joke late into the evenings. The moral issues involved in the Rodi practice have constantly been a subject of a great deal of debate - both among scholars interested in the Gurung culture and among the Gurungs themselves. Some Gurungs do not allow their children to attend the Rodi because they regard it as an immoral custom, but - to my knowledge - most of them see Rodi as a harmless or even necessary practice of the young, which is important for the maintenance of Gurung culture. Most likely, there are many kinds of Rodis, those to which one would not like to send one's children and those which are ideal places for their growth. The nature of the Rodi depends on the elders of the house and on the members of the group. However, because it is a place for adolescents and teenagers, it is not surprising that it seems to be established on the eternal gap between different generations. Rodi is always blamed if a youngster is not fulfilling his or her duties at home or school.

The all-female Rodi association provides the setting for the group musicmaking of the young. Boys and girls take an equal part in the music-making; girls sing and dance as actively as the boys do and the mädal drum player who accompanies the singing is just as often a female as a male. The girls also collect money in order to buy and repair drums for the Rodi. Previously, the songs sung in the course of the Rodi evenings used to be traditional Gurung songs. When the electronic mass media, radio sets and cassette recorders reached the Gurung

\footnotetext{
3) The literacy rate for the girls is five percent, and for the boys, eighteen percent.

4) There is disagreement about the etymology of the word. Andors states that Rodi has developed from the Gurung words tî̄, a house, and $\underline{\text { ro, }}$ which means a sleeping place (Andors 1976, 103). Another explanation refers to the Gurung concept of wool, rho (Gurung 1978).

5) Rodi is a distinctive feature of the Gurung culture. Similar kinds of institutions for the youth organised and maintained by the whole society are found only in three other cultures in the whole world. For more, see Andors 1971 and 1976.
} 
area in the early seventies, Gurung young people began to sing and compose songs in the style of radio music.

The Rodi does not function only in the sphere of entertainment of the young. At busy times, Rodi groups arrange cooperative labor groups called nogar; girls and boys go to work in the fields together. The institution of the Rodi has many enculturational functions and features of societal importance in the Gurung society. The institutionalised peer groups of young girls are interwoven into Gurung society and its basic values. In the course of their Rodi years, Gurung girls are encultured in the Gurung socio-economic structure. The Rodi institution transmits the basic values of Gurung society, group cooperation and reciprocity, and it supports the Gurung cultural identity.

Girls remain members of a Rodígroup for over ten years. A girl's contacts with her Rodí friends may continue until she begins to have children and her childcare responsibilities and increased demands of household labor take precedence over her participation in Rodi activities (Andors, 1976:219). After this, there may be no continuation of their previous relationship, especially if her marriage has taken her to another village.

The Rodi institution provides an important degree of background support for many Gurung musical performances. Traditionally, the Rodi groups organize the setting, the decorations, the necessary equipment and serving refreshments for performances of the Ghâtu dance drama ${ }^{6}$. The musicians, singers and drummers in these performances are middle-aged or older men; the dancers are young girls. Due to the supernatural dimensions of the performances, the Ghätu dancer, called ghatseri and/or ghatune, has to be a virgin of premenstrual age when she just becomes a dancer. The dancers are selected from among many voluntary young candidates. They are taken to a well to wash themselves and thereafter dressed in clean clothes. The dancing area is purified with cow urine. Those girls who "become touched by the gods" while dancing, in other words, who go into a state of spirit possession, will become new ghatunes. Once a dancer, a girl may dance until she marries. However, traditional norms of this kind are becoming looser due to the general modernisation of life and nowadays one can find even married women dancing in the Ghätu performances.

Nowadays, in many villages, cooperation between the Rodī and the Ghātu group has ended. A dance theatre called Thetar $^{7}$ which takes its model from urban music and dance performances as well as from both Indian and Nepalese movies is increasingly gaining popularity, particularly among the young. Instead of supporting Ghâtu performances, many Rodĩ groups have begun to arrange Thetar presentations. ${ }^{8}$ In these performances, girls and boys are the musicians, singers, players and dancers. The music performed in the Thetar is adapted from the mass media, or composed by male and/or female performers. The same songs

\footnotetext{
6) For more about the Ghàtu, see Moisala 1991, 201-274.

7) See Moisala 1991, 303-314.

8) In some villages the Thetar is formed by the teachers and pupils of the local school. In that case, the proceeds of the Thetar are also given to the school.
} 
are then sung in the Rodi evenings. The most recent form of musical activity connected with the Rodĩ institution is the so-called cultural groups. ${ }^{9}$ Although the name is changed, the form and content are similar to those of the Thetar.

The Rodi institution can be seen both as a maintaining and a stabilising force in the Gurung society and culture. Because of its role in the enculturation process of the young and as a supporter of traditional ceremonies, it supports the maintenance of the traditional culture and societal system of the Gurungs. In addition, it functions as a mediator between tradition and change. As demonstrated in the music-making, the Rodi supports the smooth adaptation of the society to the demands of modern life.

Although many of the Gurungs do not consider themselves Hindus, 10 the religious symbolic system of Hinduism, as well as that of Buddhism, affects the gender roles in Gurung society. Also for economic reasons, children of different sex are accorded a different kind of status and treatment in Gurung families.

Maintaining their house and property is of great importance to Gurung families. In this respect, female children bring financial loss to Gurung families. Female children will, through marriage, move away from the house and take some of the household property with them as a dowry. On the contrary, male children will actually add to the household inventory when they marry and add their wife's dowry to the family property.

A Gurung male child is encouraged to develop outward activities, to socialize at the level of the whole village collective, to gain education and a possible career as a mercenary soldier. A male child, especially the first one, is a welcomed member of a Gurung family. When the first male child reaches the age of one, ${ }^{11} \mathrm{a}$ special celebration is arranged for him. The family invites a group of men to perform a Krishna charitra, the story of Lord Krishna, for the blessing of the young child. It is hoped that he will become as brave and wise as Lord Krishna was. In this celebration, many gifts are given by relatives and friends. Nothing comparable is arranged either for female children or for other male children. ${ }^{12}$

At an early age the boys do the same household work as the girls. They may look after younger ones and carry water. After the age of ten, when they are strong enough, they are expected to herd buffalo and to participate in the work in the fields as helpers of their fathers. These tasks take place before and after school hours.

The small group solidarity of young Gurung males is much looser than that of the young females. They may form casual groups of friends when visiting Rodis; however, they are not expected to identify with one particular group of friends.

9) There are professional "cultural groups" in the biggest cities of Nepal, in Pokhara and Kathmandu. These groups give folk dance and music performances mainly for tourists.

10) The state religion of Nepal is Hinduism. Due to their Tibetan origin, nowadays an increasing number of the Gurungs identify themselves as Buddhists. Nevertheless, their religious practice is a mixture of shamanism, Buddhism and Hinduism.

11) Due to the high infant mortality rate in Nepal, 15 percents, these kinds of ceremonies are not conducted before the child has survived his first year of life.

12) For more, see Moisala 1991, 274-301. 
The group orientation comes into play in their later lives, mainly as a product of army service.

Boys are brought up with reminders of their future responsibilities as the main financial supporters of the family. In this respect they are encouraged to work hard at school and to practise sports actively, because healthy and strong young men are more likely to get jobs as paid soldiers. Boys also have a wider range of social and physical mobility during their childhood and young adulthood than girls. This is consistent with the expectation that as adults they will have to adapt themselves to a variety of social situations outside the village and to cooperate with a wider range of people (Andors 1976, 214).

The musical activities of the boys take place in equal participation with girls at the Rodi evenings. When arranging the setting for and supporting traditional musical performances, the boys may help the girls, who, however, carry the main responsibility.

After marriage ${ }^{13}$ a Gurung female is supposed to give up activities outside the family circle: her activities are shifted inside the household. The girls may still occasionally arrange cooperative labor groups for work in the fields or for collecting wood. If the girl marries into another village, she loses her peer contacts and has an opportunity to see them only when visiting her home village. However, even if she marries within the same village, her relations with her previous Rodī peers become less close. The long-term group experience gained in the course of the Rodi years does not incorporate itself into the adult life of women (Andors 1976, 237-239).

The main responsibility of married women is to maintain the household, to prepare food, to wash clothes, to clean the house, and to look after the children and livestock. They may also look after the fields close to home, and at busy harvesting and planting times they help in the fields further away. Most of women's relationships are within their kin groups, either through birth or marriage.

Following Hindu tradition, the status of a newly married woman increases when she bears her first son. Correspondingly, the position and status of a childless wife is rather weak. The blame for childlessness is placed on the woman. Most often the husband of a barren woman will marry again. ${ }^{14}$ The

13) There are different types of marriage arrangements in Gurung society. In 1975, the most common was marriage arranged by the parents of the children. A young man is consulted about a suitable girl, but the girl is never consulted or even told about the arrangements. In some cases, young people in love escape from their home village to marry and cannot return until their parents have forgiven them. If the marriage is very improper in the eyes of the parents as well as of the village, the forgiveness may take several years to come.

Both husbands and wives are allowed to announce divorce. The desire to divorce has to be pronounced three times in public in order to enforce the dissolution of the marriage. A divorced Gurung woman returns to her childhood home and is dependent on her father and brothers. Divorced Gurungs, males or females, may remarry.

Nowadays, marriage decided on the basis of negotiations between parents and children has become quite common, especially in the families of soldiers or ex-soldiers who have been subject to foreign influences.

14) Polygamy has been practised, and still is, although very rarely, among the Gurungs. 
women who do not have children explain that they have been "insulted by fate" (Andors 1976, 186).

The life path of a woman leads to easier living and increasing power the older she gets. After middle age, many women no longer have to take part in heavy rice planting. If there is a younger woman in the house, the older woman is the one in charge. At that stage, women may quite independently make decisions concerning food supplies and household activities. Men decide about field work, and often the husband and wife discuss together the work which should be done the next day.

Men have the dominant role on the public stage. ${ }^{15}$ Adult women are not expected to take part in public village meetings, even if the males of the house are absent. Men also inherit and control property. Traditionally, land was inherited by sons of the family. ${ }^{16}$ Only wealthy families could afford to give some land as a dowry to the daughters. Theoretically, an unmarried woman over thirty-five years old may claim her share, which is half of what her brother receives. In practice, this seldom happens.

Young Gurung men have more alternatives in regard to their future. They may choose to stay in their home village as rice farmers, or to move to a city for another kind of job; they may apply to the Nepalese or foreign army, or decide to continue their studies at college level. ${ }^{17}$ Whether the Gurung man is a shopkeeper, a teacher, a postmaster or a soldier, additional farming is usually necessary to make a living.

Marriage does not cause any great changes in the life of a Gurung male. He goes on living in the house of his father until, possibly, he builds one of his own. Traditionally, the youngest son is expected to remain in his parents' house and take care of them when they get old. In practice, it is not always the youngest who stays. Men also attend Rodi gatherings even after they marry, and they may continue their bachelorstyle of life for some time.

Except for the music made by children and youngsters in the Rodi gatherings and in the Thetar performances, public Gurung music is sung, played and mostly danced by adult men. The three main musical ceremonies, the Ghätu, the Krishna chalitra and the Sorathi ${ }^{-18}$, are performed by a group of middle-aged and older male singers and three to four male drum players. In the Krishna charitra and in the Sorathi performance, the dancers are males. In the Krishna charitra, two of

15) Of course, there are exceptions to this. Some Gurung women are able to gain untraditional positions in Gurung communities. Their exceptional roles are not supported by the community; however, once attained, they are allowed. Ellen Andors notes that "Gurung women appear to be more actively involved in outside politics than women of other neighboring ethnic groups" (Andors 1976, 233). For an exceptional life story of a Gurung woman, see McHugh, 1985.

16) Recently a law was established in Nepal according to which unmarried women have an equal right to inherit land. This law, however, is not yet commonly known and it will take time before it is followed in practice.

17) Some Gurung women have also gained higher education at college where they have become teachers.

18) See Moisala 1991, 338-341. 
four dancers are dressed in female costumes; they represent Radhā, the beloved of Lord Krishna. In the Sorathi, male dancers dressed in female costumes do not play any particular female role, but are there to "make the performance more beautiful".

Many Gurung men spend much of their lives away from home in foreign army service, in the Gurkha regiments, in the police forces of India, Singapore, or Hong Kong, or even in England. Their absence from the village may last from sixteen to twenty-four years. Their families may stay with them in the place of service for two years. Every three years the soldiers get a six-month vacation. The vast majority of men eventually return to the village and resume their lives as farmers. Meanwhile, the Gurung women keep up the family fields, households and village life in general.

During the years of their army service, the Gurung males continue supporting the musical traditions of the Gurung community. On their vacations from army service, they are expected to host traditional musical performances and contribute money for them, because soldiers are known to have large sums of money. The status of a soldier is directly related to the amount which he pays towards these performances. The money collected through the performances is often given to the village fund and used for common village purposes. In this way, the adult Gurung males, although absent from the daily life of the community, still continue supporting the collective.

Women do not have similar socially acceptable routes for their activities. For them, the right to support music and act on the collective and public stage in music is restricted by social norms after marriage. After they marry, when they are expected to limit their activities to the family and domestic affairs, they are not supposed to perform music or to dance in public; it is not "proper" that a married women performs or is even interested in music. Despite the fact that nowadays there are an increasing number of exceptions to these norms, ${ }^{19}$ the attitudes which limit the possibilities for women to make music are still there.

Singing, melodic shouting and humming in the fields and at home are common activities of Gurung women. According to my observations, men did them less frequently. This, however, is not regarded as music (baja; among educated Gurungs called sangit), but as an inseparable part of the main activity: singing lullabies is not singing but "putting baby to sleep", and singing while cutting rice is "cutting rice" only. According to Gurung musical conceptualisation, music is collective and public in nature. Musical sounds made alone and without an audience are not regarded as music. Thus, musical sounds such as those which are made by women to accompany work are not considered to be music.

The participation of Gurung women in music making is also limited by esthetic evaluations. The singing voice of a young female is considered to be beautiful,

19) In 1975, I observed only one married Gurung woman dancing and singing in a public performance. She was a teacher who had attended college. Obviously her public musical activities aroused mixed feelings in the village audience. In 1985, I made several observations of performing married Gurung women, although they were still the exception. 
but the singing of an older female is thought peculiar. These judgements do not directly prevent older Gurung women from participating in group singing, but these kinds of esthetic norms effectively prevent it in practice. Gurung women who have tried to join a singing group of men have been "laughed out" of their attempt.

The older Gurung women never dance or play drums in public. When asked if they ever do it, even in private, they are amused and deny having any musical activities. Even if the woman remembers being an active drum player or dancer in her youth, she claims to have given up her musical activities when she married.

But musical women have developed a socially acceptable way to express their talents; when they have met with sorrow, such as when a relative has died or their son has made an unhappy marriage, they cry, simultaneously improvising words and melody. This is not music either according to Gurung musical conceptualisation, but is simply called "crying". (See Example 1.)

Example 1. Lament of a woman at her father's cremation.

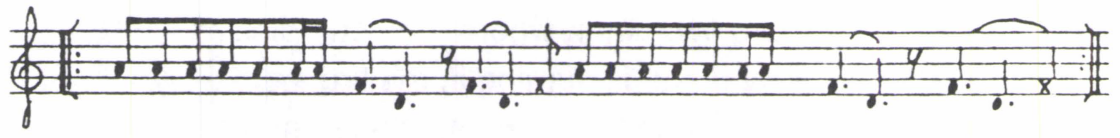

My dear father, where are you going?

Why do you leave me behind, why do you leave us like this?

dear father, where are you going?

All your relatives have come here,

why do you leave us in such a grief?

Why did you not want to stay with us?

My king, my father, take me with you, if you go away, with whom should I live 20 , my father, how can I calm my mind?

You stayed here only a short time, you went to the King's palace, you went to the God's home. Why don't you take me along? I will die of grieving and weeping, my father, and I will die in vain. I would have rather died instead, I cannot see you, where are you now, what are you doing now? You left us, you forgot us,

20) The lamenting woman was unmarried and lived in her father's house. 
how can I forget you?

I never dreamed you would die,

how could it happen in real life?

My body will grow thinner and thinner,

how can I stay in this world anymore?

All your words were nectar to our ears.

You were never ill, nobody knew you would die like this, my dear father, where are you?

We cannot get you back by weeping and grieving, you do not feel anything.

You will take your new birth in the God's palace, may you get to the heaven.

Why did you go alone?

(At this point, the daughter recited a blessing over her father and the corpse was taken to the pyre.)

Oh, my father, where are you going?

My father is burning in the fire,

how can I live now, oh, my father.

\section{The interplay of gender and music}

The social gender roles are learned from early childhood and they are followed in adult activities. An interesting thing is that the music making of Gurung children and young people is not restricted by social norms but takes place equally among boys and girls. This equal participation emphasises the Gurung comprehension of the different sexes; both sexes are required for completion. The girls, through their all-female Rodî institution, have a crucial task as supporters and organizers of both children's and adults' musical activities. Girls' activities as providers of the setting for informal music, as well as for the Ghätu and the Thetar performances, can be regarded as one part of their training in "background" support.

Traditionally, the public dancing of adult women is not considered proper but nowadays one can see young married women participating in the Thetar performances. Commonly, these dancers are modern women with a strong will, who do not care about their reputation in the eyes of the more conservative villagers. So how should we, in this context, interpret the central role of female dancers of premenstrual age in the Ghātu dance? The performance of the Ghätu represents the animistic world view of the traditional Gurung society, according to which the supernatural dimension - gods and local deities - is continually influencing people's lives. When the ghatunes become "touched by the gods", the belief in the presence of the gods is enforced again. The ghatunes must be 
virgins in order to be suitable for the gods. If this requirement is meant to be also a moral statement to guide the behaviour of young women, it is possible, however, that it can also be a practical arrangement. Young "untouched" females are probably found to be most susceptible to fall into a trance.

Marriage seems to be the watershed which crucially divides musical activities according to gender. In the course of adult married life, the classical opposition of male and female positions (females stay within the domestic sphere, men share the public stage, see Rosaldo 1974, 22-23) is demonstrated in the Gurung musical activities. The youngsters and men make the public music and the participation of adult women in the public music-making is restricted by esthetic evaluations and social norms. Their musicality can find expression only within the household, in privacy. The conceptualization of music of the Gurungs limits women's role as music-makers even further, because musical sounds made privately out of public view are not considered to be music (baja) at all. Married Gurung women have no possibility of making socially acceptable music.

The interplay of gender and music among the Gurungs supports the different scopes of the lives of Gurung females and males, which are present from their early childhood. The musical practice follows the different economic and social responsibilities of Gurung males and females. The permitted actions of gender groups in relation to music are sanctioned and enforced by esthetic norms. Musical behaviour, among many other cultural aspects, encultures Gurung children into the Gurung gender order. Changes in gender roles are also reflected in music-making - perhaps even before they are noticeable in other aspects of culture.

It seems that the actions of the different genders in music-making follow the special dualistic characteristic of music. On the one hand, music is formative, repetitive and thus conservative in nature. This is reflected also in gender-based musical behavior. The actions of different genders in music display the most traditional and conservative values of a society. On the other hand, music is innovative and ever looking to the future, developing itself. In this respect, people may cross or reverse traditional gender roles in music-making situations. The exceptional atmosphere of musical performances allows people to relieve tension and cut across gender-based restrictions.

\section{References cited}

Andors, Ellen: 1971 The Rodighar And Its Role in Gurung Society. Contribution to Nepalese Studies. Journal of the Institute of Nepal and Asian Studies. (12):10-24. Nepal: Tribhuvan University.

- 1976 The Rodi: Female Associations among the Gurung of Nepal. Unpublished dissertation, Columbia University, USA.

Gurung, Jagman: $2035^{21}$ Gurung Jati Tatha Sanskati. Savoghikar Lekhakama Suratrima.

21) The year 1978 of the Christian era was 2035 of the Vikram era. 
Moisala

Pokhara: Sender Press.

Herndon, Marcia and Susanne Ziegler (eds.): 1990 Music, Gender, and Culture. Wilhelmshaven: Florian Noetzel Verlag.

Koskoff, Ellen (ed.): 1987 Women and Music in Cross-Cultural Perspective. Urbana: University of Illinois Press.

McHugh, Ernestine: 1981 The Women of Tebas, Feminine Perspective in Gurung Culture. Kailash, a Journal of Himalayan Studies, 13 (1-2):45-71. Kathmandu.

- 1986 The Social, Cultural, and Personal World of the Gurungs of Nepal. Unpublished dissertation. University of California, San Diego, Department of Anthropology.

Moisala, Pirkko: 1991 Cultural Cognition in Music. Continuity and Change in the Gurung Music of Nepal. Jyväskylä: Gummerus.

Rosaldo, Michelle Zimbalist: 1974 Theoretical Overview. In Women, Culture, and Society, edited by Michelle Rosaldo and Louise Lamphere. Stanford: Stanford University Press. 